\title{
The cost of being a caring mother: the ignored factor in the reproduction of marine invertebrates
}

\author{
Miriam Fernández, ${ }^{1,2}$ Christian \\ Bock $^{1}$ and Hans-Otto Pörtner ${ }^{1}$ \\ ${ }^{1}$ Alfred-Wegener-Institut, \\ Columbusstr., D-27568, \\ Bremerhaven, Germany. E-mail: \\ mfernand@genes.bio.puc.cl \\ ${ }^{2}$ Estación Costera de \\ Investigaciones Marinas and \\ Departamento de Ecología, \\ Facultad de Ciencias Biológicas, \\ Pontificia Universidad Católica \\ de Chile, Casilla 114-D, Santiago, \\ Chile.
}

\begin{abstract}
Investment in reproduction ranges from gamete production to active parental care, and marine invertebrates span this range. However, the cost of parental care has not yet been systematically quantified, nor incorporated into life history studies of marine invertebrates, in contrast to most other animal taxa. Since oxygen is a limiting factor in egg masses of marine invertebrates, we studied patterns of oxygen partial pressure over time in embryo masses of Brachyuran crabs, and correlated these results with the cost of providing oxygen to the embryos. We found that: (1) oxygen is limiting in the embryo masses, (2) female crabs show an active brooding behaviour that we think helps to provide oxygen to the embryo mass, and (3) there is a substantial parental investment associated with brooding behaviours. Oxygen limitation and parental investment seem to be associated in many taxa of marine invertebrates, and we suggest that oxygen provision to the embryos may be a critical factor determining parental investment in this group.
\end{abstract}

\section{Keywords}

Brachyuran crabs, brooding, marine invertebrates, oxygen, parental investment.

Ecology Letters (2000) 3:487-494

\section{INTRODUCTION}

In spite of the difficulties in determining the costs and benefits of parental care, there is no doubt that parental care has a cost, that the benefits are large, and that both factors have important implications in shaping life history patterns (Krebs \& Clutton-Brock 1991; Stearns 1992). Gamete production represents the principal form of parental expenditure in many animals, and in others the cost of parental care ranges from the production of yolked embryos to the care of or provision for the young after hatching (Krebs \& Clutton-Brock 1991). Marine invertebrates span the range between both extremes of parental expenditure and care; however, as of yet, the actual cost of parental care has neither been systematically quantified, nor has it been formally and carefully incorporated into life history studies (Krebs \& CluttonBrock 1991), comparative studies of investment in reproduction (e.g. Browne \& Russell-Hunter 1978; Brey 1995), or models (e.g. Vance 1973; Perron 1981). It is tempting to think that if investment in parental care is considerable among terrestrial invertebrates (e.g. Wilson 1971; Zeh \& Smith 1985), reptiles (e.g. Shine 1988), birds (e.g. Lack 1968; Brown 1987), and mammals (e.g. Clutton-Brock et al. 1981), it could also be among marine invertebrates.
Certainly, the aspects of parental care that appeal to our anthropocentric perception of caring are not common among marine invertebrates (Krebs \& Clutton-Brock 1991). However, provision of oxygen to embryos, a form of parental care, may occur across taxa in marine invertebrates, despite the diversity of development modes. Oxygen limitation in embryo masses could explain the allometry in brood size, and thus the association between brooding and small body size in marine invertebrates (Strathmann \& Strathmann 1982). Oxygen limitation due to constraints in oxygen diffusion in packed embryos have been suggested by several authors (e.g. Crisp 1959; Perron \& Corpuz 1982; Chaffee \& Strathmann 1984; Pechenik 1986; Strathmann \& Strathmann 1995). Strong oxygen gradients have been detected in gelatinous embryo masses of gastropods (e.g. Cohen \& Strathmann 1996), and there is some evidence that parental investment (e.g. addition of gel as extraembryonic material) among marine invertebrates may be driven by oxygen limitations in the egg mass (Lee \& Strathmann 1998). This simple physiological constraint on brood care may link complexes of life history traits with ecological and evolutionary consequences (Strathmann \& Chaffee 1984), if we consider broadcasting as the cheapest alternative to ventilating the large embryo masses produced by large adults. 
Brachyuran crabs are one of the exceptions to the association between brooding and small body size in marine invertebrates (Strathmann \& Strathmann 1982), and are among the largest marine brooders in nature. Recent studies show that oxygen is also limiting in crab embryo masses, and suggest that females may be able to detect conditions in the embryo mass related to oxygen availability (Naylor et al. 1999). Here we show, using two crab species (Cancer pagurus and Maja squinado) and several approaches (Magnetic Resonance Imaging, microoptodes, and behavioural studies) that (1) oxygen is limiting in the embryo masses, (2) female crabs show an active brooding behaviour that we think helps to provide oxygen to the embryo mass, and (3) there is a substantial parental investment associated with brooding behaviours. Although there are several aspects (and costs) of parental care, we focused only on the cost related to the provision of oxygen to the embryos, because there is some evidence that parental investment among marine invertebrates may be driven by oxygen limitations in the embryo mass (Strathmann \& Strathmann 1995). The advantages of selecting crabs as models for this study are threefold: first, crabs are an exception to the association between brooding and small body size among marine invertebrates (Strathmann \& Strathmann 1982); second, brooding behaviour in crabs seems to be related to the provision of oxygen (Naylor et al. 1999) and third, there is evidence that crabs show an active brooding behaviour (Wheatly 1981; Naylor et al. 1999). Our study highlights a key aspect shaping life history patterns, well studied in many animal taxa (Krebs \& Clutton-Brock 1991 and references therein) but virtually ignored in marine invertebrates.

\section{MATERIALS AND METHODS}

For all the experiments reported below we used embryos (or females carrying embryos) in early stages of development (embryos with cleavage and yolk reduced to about $75 \%$ of embryo volume, eyes barely visible, not developed). For M. squinado we also used late stage embryos (embryos with well developed eyes, pumping heart, and appendages). We conducted the following experiments.

\section{Magnetic resonance images}

We used magnetic resonance imaging techniques (MRI) in order to determine patterns of water flow through the embryo mass. The embryo mass was monitored with a flow sensitive gradient echo MRI sequence $(\mathrm{TR}=76.5$ $\mathrm{ms}, \mathrm{TE}=6 \mathrm{~ms}$, Matrix: $256 \times 192, \mathrm{FOV}=11.75 \times 13$ $\mathrm{cm}$, four slices, slice thickness: $2 \mathrm{~mm}$, flip angle $\alpha=45^{\circ}$, scan time $2 \mathrm{~min})$. Crabs were allowed to move their legs and abdomen, whereas the body of the animal was fixed (to a bar on top of the aquarium) to prevent movement artifacts. Animals were not kept longer than $5 \mathrm{~h}$ inside the magnet. Between eight and 16 repetitions were carried out to obtain time series of water flow through the embryo mass. Sediments cannot be used in the MRI, but we think that this factor has no major effect since it is well known that ovigerous females of the two crab species used here do not bury frequently (although they may dig hollows in the sediment; Naylor et al. 1997, 1999; Naylor and Taylor 1999).

\section{Microoptodes and female behaviour}

Optic fibers with a tip diameter between 20 and 50 microns were used to monitor oxygen continuously in the centre of the embryo mass. A small hole $(0.8 \mathrm{~mm})$ was drilled into the abdomen (III segment) of brooding females, and a plastic tube (of variable length depending on embryo mass diameter) was inserted and fixed to the carapace. The tube fixed the microoptode in place during the experiment. The microoptode was inserted into the tube after calibration at $12^{\circ} \mathrm{C}$ in a solution saturated with $\mathrm{NO}_{3} \mathrm{~S}_{2}(0 \%$ air saturation) and in aerated water $(100 \%$ air saturation). Both the tube and the microoptode were fixed to the carapace using cyanoacrylate glue and dental wax. The experiment was conducted at constant temperature $\left(12^{\circ} \mathrm{C}\right), 24 \mathrm{~h}$ after female recovery from handling to reduce behavioural artifacts, in tanks filled with an 8-10 cm layer of sand and seawater. After $1 \mathrm{~h}$ of acclimation, oxygen partial pressure $\left(\mathrm{PO}_{2}\right)$ in the centre of the embryo mass was monitored continuously for $24 \mathrm{~h}$ (Table 1 depicts the fraction of time embryos from the centre of the mass spent in the various ranges of $\mathrm{PO}_{2}$ ). Previous approaches to estimate $\mathrm{PO}_{2}$ in the centre of the embryo mass were based on samples obtained from the embryo mass, not taking into consideration the time elapsed since the last ventilation (Naylor et al. 1999). Our method allows estimation of $\mathrm{PO}_{2}$ over time, regardless of when oxygen in the embryo mass is sampled, and assesses the actual levels of $\mathrm{PO}_{2}$ that the embryos experience during early development in the centre of the embryo mass. Female size ranged between 135 and $180 \mathrm{~mm}$ for C. pagurus, and between 100 and $150 \mathrm{~mm}$ for $M$. squinado in all experiments, but the size of the embryo mass in both species was comparable (between 4 and $6 \mathrm{~mm}$ diameter). In both species the same embryo stage was used (early, defined above). For each female, we estimated the percentage of the time that the embryos from the centre of the embryo mass (early stages) spent at different $\mathrm{PO}_{2}$ randomly selecting and analysing 2 -h of continuous oxygen measurements obtained with the microoptodes (from each 24-h trial). The mean percentage of the time that the embryos spent at different $\mathrm{PO}_{2}$ was compared 
Table 1 Embryo oxygen consumption and fraction of time at each oxygen partial pressure in the centre of the embryo mass.

\begin{tabular}{|c|c|c|c|c|c|}
\hline \multirow[b]{2}{*}{ Variable } & \multirow{2}{*}{$\begin{array}{l}\text { Range of oxygen } \\
\text { partial pressure }(\mathrm{mmHg})\end{array}$} & \multicolumn{2}{|l|}{ C. pagurus } & \multicolumn{2}{|l|}{ M. squinado } \\
\hline & & Early & Late & Early & Late \\
\hline Oxygen & $<15.9$ & $0.277(0.029)$ & & $0.105(0.043)$ & $0.294(0.118)$ \\
\hline consumption & $15.9-39.7$ & $0.569(0.053)$ & & $0.114(0.032)$ & $0.581(0.118)$ \\
\hline \multirow[t]{3}{*}{ of the embyros } & $39.7-79.4$ & $0.603(0.067)$ & & $0.143(0.024)$ & $0.766(0.118)$ \\
\hline & 79.4-119.1 & $0.674(0.087)$ & & $0.179(0.022)$ & $0.752(0.087)$ \\
\hline & 119.1-158.8 & $0.664(0.090)$ & & $0.189(0.021)$ & $0.578(0.087)$ \\
\hline Mean & $<15.9$ & $50.7(4.1)$ & & 0 & \\
\hline \multirow[t]{4}{*}{ percentage time } & $15.9-39.7$ & $14.6(4.9)$ & & $2.3(0.9)$ & \\
\hline & $39.7-79.4$ & $20.1(1.7)$ & & 0 & \\
\hline & 79.4-119.1 & $17.2(4.3)$ & & $41.9(15.5)$ & \\
\hline & 119.1-158.8 & $2.6(1.53)$ & & $52.6(16.9)$ & \\
\hline
\end{tabular}

Mean oxygen consumption of crab embryos at different oxygen partial pressures for both crab species. For C. pagurus only data for early embryos were available. The mean percentage of the time that the embryos spent at different $\mathrm{PO}_{2}$ was estimated using continuous oxygen measurements obtained with the microoptodes. The general patterns of oxygen availability are shown in Fig. 2, and the summary statistics for all the trials are presented in this table. Values in parentheses indicate one standard deviation.

using a two-way ANOvA (factors were species and $\mathrm{PO}_{2}$ ). When necessary, transformations were used.

Females were videotaped during the experimental period to monitor female behaviour. Non-brooding females were also placed in the experimental tanks (one per tank), to monitor their behaviour after 1-h acclimation. Female brooding behaviour was characterized based on 24-h recordings, with red light during the night. Brooding females (without microoptodes) were also monitored to assess any artifact caused by the microoptodes, and no effect of microoptodes on female behaviour was observed. At least five replicates were conducted for each combination of female condition (brooding, carrying early or late embryos, and nonbrooding) and species. The frequency at which each brooding behaviour was performed was estimated and compared between species using a $t$-test.

\section{Brooding costs}

We concentrated on estimating two of the many possible potential costs of brooding: the "mechanical cost of brooding" (egg losses may occur due to the active movements performed by females), and the "energetic cost of ventilation" (changes in oxygen consumption of brooding females when compared to nonbrooding ones). Since we assumed that changes in oxygen consumption between brooding and nonbrooding females was due to oxygen provision to the embryos, we used indistinctly the terms metabolic cost of brooding, of ventilation, and differences in oxygen uptake between brooding and nonbrooding females. The mechanical cost of brooding was estimated under laboratory conditions, with experimental tanks $(50 \times 40 \mathrm{~cm})$ conditioned with sediment and maintained at $12^{\circ} \mathrm{C}$, and females carrying large embryo masses. A control (ovigerous females not ventilating) could not been included in the experimental design, since ventilation cannot be prevented. The embryos lost in the tank during the experimental period were weighed (wet) and transformed to dry weight. Daily embryo loss was estimated only for early embryos, and taking into account the initial brood dry weight of experimental females. The estimates are reported in mean daily egg losses per unit of brood weight $(\%)$, and a $t$-test was used to compare mean losses between species.

In order to assess the "energetic cost of ventilation", and compare it across species, oxygen consumption of brooding and nonbrooding females was estimated. The experiment was conducted using female crabs (with large embryo masses, early embryo stage) and respiration chambers. Unfortunately, we never had access to females of C. pagurus carrying large masses of late embryos (see Results), so for late embryos only $M$. squinado was used. Respiration chambers (11 L) were placed in a large reservoir tank (100 L) of filtered seawater $(0.2 \mu \mathrm{m}$, calibration as above). The rate of oxygen depletion was monitored continuously with oxygen electrodes connected to a chart recorder. We estimated oxygen consumption of egg carrying females and also of control females (with their embryos removed; measured $24 \mathrm{~h}$ after embryo removal). At least five replicates for brooding and nonbrooding females of each species were conducted. Using the relationship between female and embryo mass dry weight (log-log), oxygen consumption of the embryos (see below) was extrapolated for the whole mass. The expected oxygen consumption of the embryo mass was then subtracted from the estimated oxygen consumption of the brooding female and the embryos, in order to estimate oxygen consumption of brooding females. 
Oxygen consumption of brooding and nonbrooding females of both species was compared using a two-way ANOVA. A one-way anOva was used to test for differences in oxygen consumption of nonbrooding and brooding females (carrying early and late embryos) of $M$. squinado.

\section{Oxygen consumption of crab embryos}

Oxygen consumption of early ( $C$. pagurus and $M$. squinado) and late (M. squinado only) developmental stage embryos was recorded under constant temperature $\left(12^{\circ} \mathrm{C}\right)$, using a double wall, closed microchamber filled with 2 $\mathrm{mL}$ of stirred $(0.2 \mu \mathrm{m})$ seawater with added antibiotic. After calibration (see above) a small number of embryos were removed from the brooding females (maintained also at $12^{\circ} \mathrm{C}$ ) and placed on a fine grid in the microchamber. We used a stir bar under the grid to homogenize oxygen partial pressure inside the chamber, avoiding (1) direct contact between the stir bar and the embryos, which could produce some disturbance and artificially increase oxygen consumption; and (2) oxygen depletion near the embryos when unstirred (Naylor et al. 1999). Oxygen depletion was monitored continuously with oxygen electrodes (variable time depending on the developmental stage of the embryos until oxygen was depleted to $15.9 \mathrm{mmHg}$ ), and then the embryos were weighed. A minimum of eight measurements were conducted for early and late embryos and for each species. Oxygen consumption per unit of time and weight was estimated for different $\mathrm{PO}_{2}$ (15.9, $39.7,79.4,119.1$, and $158.8 \mathrm{mmHg}$ ) and compared among different partial pressures for early embryos of each crab species, and late embryos of $M$. squinado.

\section{RESULTS}

We first assessed if oxygen is a limiting factor in the centre of the embryo mass of the two studied species of Brachyuran crabs, and using MRI and microoptodes, we determined patterns of water flow through the embryo mass and $\mathrm{PO}_{2}$ continuously in the centre and the border of the embryo mass. Water flow through the embryo mass showed different patterns between species; in $C$. pagurus no flow or low flow rates were detected in most areas of the embryo mass (Fig. 1, except for a region of high, unidirectional flow in the upper layer of the embryo mass). In most regions flow was imperceptible. The opposite pattern was observed in $M$. squinado, where water flow was supplied from all sides and was always present and homogeneously distributed in the whole embryo mass most of the time (Fig. 1). Both species showed high oxygen levels at the border of the embryo mass (Fig. 2a, b), but oxygen availability in the centre reflected the pattern of water flow detected with the MRI.
Oscillations in $\mathrm{PO}_{2}$ were observed in C. pagurus, with short periods of high oxygen availability (Fig. 2c), and permanent high $\mathrm{PO}_{2}$ in $M$. squinado, although small oscillations could also be observed (Fig. 2d; see Table 1).

These patterns of water flow and oxygen supply were closely related to activity levels of the females, and the costs of oxygen provision. We identified three types of behaviours that were exclusive to brooding females. Abdomen flapping was the most common behaviour associated to brooding, often accompanied by strong beating of the plepodos. Females of $M$. squinado frequently introduced the chelae into the embryo mass (no statistical comparison was conducted because this behaviour was not observed in $C$. pagurus, although it may occur later in embryo development). Only in rare cases did females $M$. squinado raise up on their legs (this occurred more often in females with late embryos). Frequently this behaviour occurred before abdomen flapping. We found that $C$. pagurus displayed a very low level of activity, while brooding females of $M$. squinado were quite active (Fig. 3a), showing higher frequency of abdomen flapping $(P<0.001)$ and use of the chelae.

We estimated experimentally two costs that could be associated with female behaviour and oxygen provision to the embryos: a mechanical cost (embryo losses) and an energetic cost (changes in oxygen consumption in comparison to nonbrooding females). Embryo losses were not significantly different between females of $M$. squinado and $C$. pagurus (only for early embryos, Fig. 3b; $t$-test $=-0.66$, d.f. $=9, P=0.52$ ). The lack of difference in oxygen consumption of brooding and nonbrooding females in $C$. pagurus, and the striking increase in oxygen consumption of brooding females of the more active $M$. squinado precluded us from testing for the main effects (ANOVA: Species $F=38.5$, d.f. $=1,26, P<0.00001$; Nonbrooding females: $F=4.9$, d.f. $=1,26, P=0.036$; Interaction term: $P=0.025$, Fig. $3 \mathrm{~b})$. Brooding females of $M$. squinado carrying large masses of late embryos were available, and included in the comparison. In this species, brooding females consumed a significantly larger amount of oxygen per unit of female dry weight than the controls (ANOva: $F=5.85$, d.f. $=2,23$, $P=0.0088$; Fig. 3b), but no differences were detected between females carrying early and late embryos $(P>0.05)$.

Both crab species showed opposite patterns of oxygen availability in the centre of the embryo mass (ANOVA percentage of the time that embryos are exposed to different $\mathrm{PO}_{2}$; Interaction: $F=10.76$, d.f. $=4,75, P<$ $0.0001)$, and these differences may affect oxygen uptake of crab embryos (Table 1). Embryos of C. pagurus spent most of the time at oxygen levels below $15.9 \mathrm{mmHg}$ while embryos of $M$. squinado are exposed to high $\mathrm{PO}_{2}$ for most of the time (Table 1). At $\mathrm{PO}_{2}$ lower than $15.9 \mathrm{mmHg}$, oxygen uptake of the embryos decreased dramatically for 

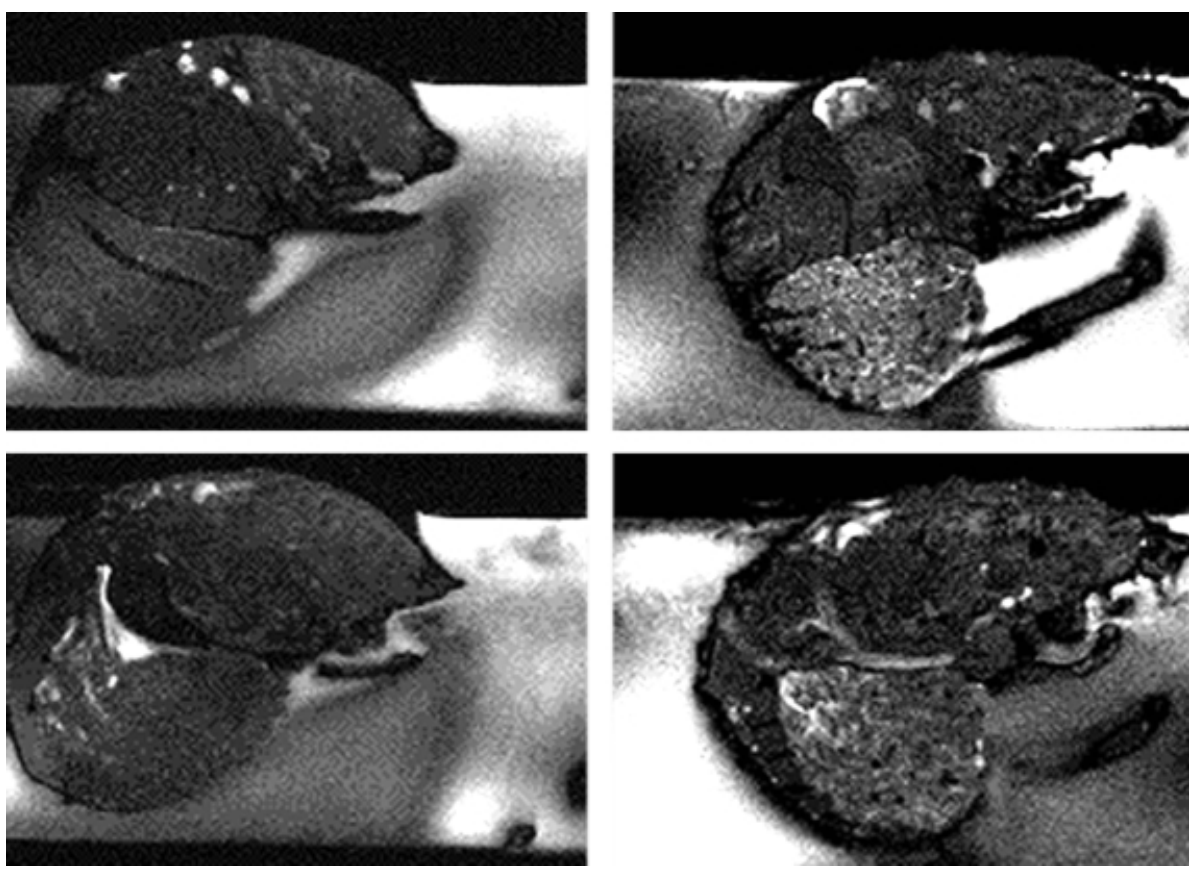

Cancer pagurus
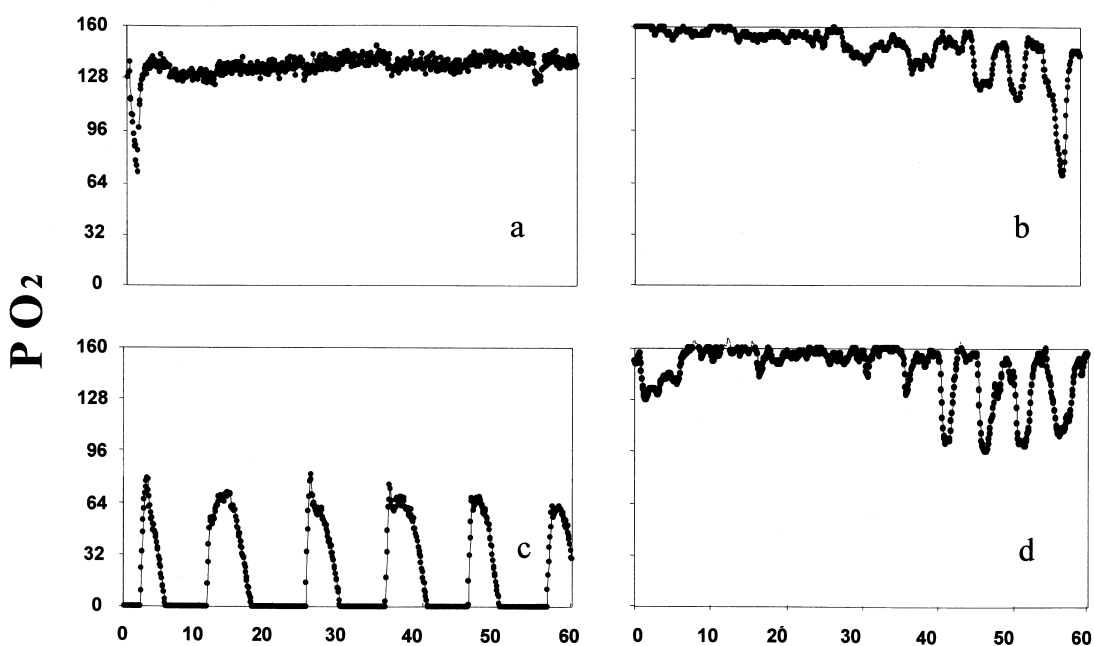

Time (min)
Figure 1 Flow sensitive magnetic resonance imaging. Side view of $C$. pagurus (left) and $M$. squinado (right). The anterior part of the crab is to the right of each image; the egg mass is underneath the crab. The images show water flow through the embryo mass. Signal sensitivity is proportional to water flow (white indicates flow, dark indicates no flow). Note the flow through the vessels of the animals, through the egg masses, and also the effect of the use of the chelae by $M$. squinado.

Figure 2 Oxygen partial pressure in the embryo masses of $C$. pagurus and $M$. squinado. Patterns of $\mathrm{PO}_{2}$ on the border ( $\mathrm{a}$ and $\mathrm{b}$ ) and in the centre ( $\mathrm{c}$ and $\mathrm{d}$ ) of the embryo mass of C. pagurus (left) and M. squinado (right). The patterns are representative of each species.

both species, and this effect was stronger for late stages (Table 1; Anovas (Oxygen consumption of crab embryos): Early stages, C. pagurus (ln): $F=4.66$, d.f. $=4,60, P<0.002$; $M$. squinado (square-root): $F=2.2$, d.f. $=4,80, P<0.08$; Late stages, $M$. squinado (ln): $F=3.4$, d.f. $=4,37, P=0.018)$.

\section{DISCUSSION}

We found that brooding female crabs adopted very clear behaviours, not present in nonbrooding females, and based on their frequency, and patterns of $\mathrm{PO}_{2}$ in the centre of the embryo mass for the two studied species, we suggest that these behaviours are related to oxygen provision to the embryos. Not only are there specific brooding behaviours (e.g. abdomen flapping, use of the chelae), but also, for any given embryo stage the brooding strategy is not uniform among crabs species; $M$. squinado exhibited higher frequency of brooding behaviours than C. pagurus, and showed higher $\mathrm{PO}_{2}$ in the centre of the embryo mass. We also suggest that there is a cost associated to brooding not yet considered in estimations of reproductive investment among marine invertebrates. 

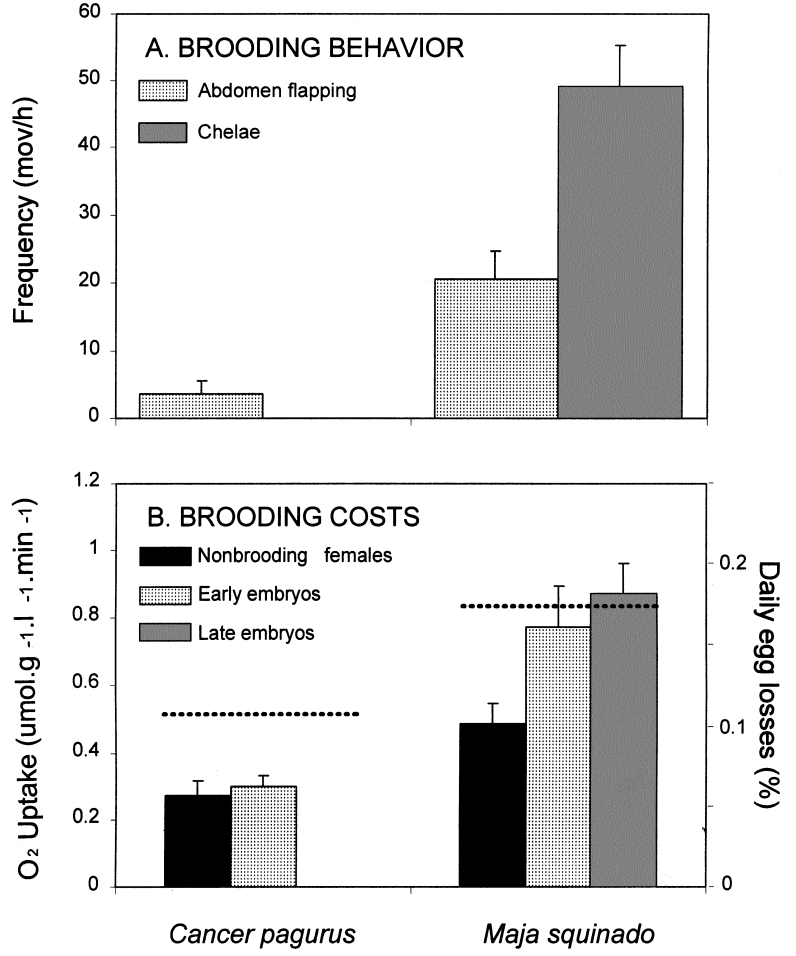

Figure 3 Brooding behaviour and expenditures. Brooding behaviour in $C$. pagurus and $M$. squinado (a), and cost of brooding (b). Two types of brooding behaviour were recorded: abdomen flapping and use of the chelae. Oxygen uptake of brooding females is always after discounting oxygen uptake of the embryos. Vertical lines indicate standard error. Horizontal lines indicate mean daily egg losses (\%).

Although we did not attempt to correlate each behaviour with actual oxygen levels in the centre of the embryo mass, the strong correspondence between patterns of water flow, oxygen availability, and activity levels (frequency of movements or behaviours) in both species suggests that female behaviour plays a role in supplying oxygen to the embryos. The possible relationship between female behaviour and oxygen provision has been mentioned in the literature on several occasions (Williamson 1904; Naylor et al. 1997). However, the relationship between patterns of oxygen provision, and the frequency at which females perform each behaviour was not formally studied (Naylor et al. 1999), and previous reports of $\mathrm{PO}_{2}$ within the embryo mass are not comparable (Naylor et al. 1999). Increases in $\mathrm{PO}_{2}$ in the centre of the embryo mass occur only during abdominal flapping in Cancer setosus, while other behaviours (e.g. maxilliped beating, pereiopod poking) were observed when oxygen availability in the centre of the embryo mass was low (Baeza \& Fernández, unpublished work). Other possible mechanisms of oxygen provision to the embryos have been suggested (e.g. gill ventilation, Naylor \& Taylor
1999; Naylor et al. 1999), although a direct correspondence between $\mathrm{PO}_{2}$ in the embryo mass and patterns of gill ventilation has not been shown. Dramatic changes in the branchial chamber pressure between brooding and nonbrooding females point to the possible importance of this factor (Naylor \& Taylor 1999). The relative importance of gill ventilation and abdomen pumping may be related to habitat (Naylor \& Taylor 1999) or developmental stage of the embryos.

The role of female behaviour in providing oxygen to embryos may be critical for embryo development, if we consider that oxygen consumption of crab embryos is strongly affected at low $\mathrm{PO}_{2}$ (Wheatly 1981; Naylor et al. 1999). This idea is supported by experiments showing that isolated embryos of Carcinus maenas develop faster and show higher survival than embryos attached to the female (Hartnoll \& Paul 1982). The effect on development of the dramatic differences in $\mathrm{PO}_{2}$ that embryos experience during very short periods of time (about $15 \mathrm{~min}$ ) is unknown. We think that differences in oxygen supply to embryos may affect their developmental time; embryo development takes longer in $C$. pagurus than in $M$. squinado (personal observation). Asynchrony in development may be another consequence of oxygen limitation in the centre of the mass. Asynchrony in embryo development has been reported for invertebrate species that embed their eggs in gelatinous masses (Chaffee \& Strathmann 1984; Strathmann \& Strathmann 1995; Cohen \& Strathmann 1996). Ongoing research on another Cancer species (C. setosus) suggests that female behaviour changes throughout embryo development, with females adopting a more active behaviour and increasing oxygen supply as the embryos develop and demand more oxygen (Fernández \& Pardo, unpublished work). Although it is not clear what triggers female brooding behaviour (Naylor et al. 1999; Naylor \& Taylor 1999), the change to more active behaviour as eggs develop could help the inner embryos to develop in synchrony with the outer embryos. It may be active female behaviour that allows some invertebrate taxa (e.g. Brachyuran crabs) to brood at larger sizes.

We also showed that there is a substantial cost associated with brooding behaviours. The cost of performing specific behaviours that may help provide oxygen to the embryos could be twice as much as the standard metabolism in M. squinado, and egg losses, probably due to ventilation, are substantial (10-13\% through the brooding period). Egg losses have been reported for several species of Brachyuran crabs (Kuris 1991 and references therein). This substantial investment in reproduction, namely parental care, is an underestimation since only some of the costs have been considered. Furthermore, the effect of brooding on females can be more dramatic if we consider that, in 
general, brooding female crabs do not feed (Edwards 1979; Howard 1982; but see Naylor et al. 1997). The lack of difference in oxygen consumption between brooding and nonbrooding females in $C$. pagurus very likely reflects the passive behaviour of females with early stage embryos (in contrast to $M$. squinado), but may also be due, to some extent, to an underestimation of the cost of brooding. We assumed that all embryos in the mass consume oxygen at the same, maximum rate; however, an important fraction of the inner embryos are consuming substantially less oxygen (due to low $\mathrm{PO}_{2}$ ). The cost of brooding may dramatically increase throughout the brooding period, since female brooding behaviour changes (Fernández \& Pardo, unpublished work). Although the conclusion that parental care (brooding) is costly may sound trivial, especially considering the literature accumulated on this topic in other taxa (Krebs \& Clutton-Brock 1991 and references therein), it has not yet been considered in the analysis of life history trade-offs in marine invertebrates. The cost of reproduction in marine invertebrates is estimated using gonad weight or weight of the egg mass, regardless of whether the studied species broods or broadcasts (e.g. Browne \& Russell-Hunter 1978; Brey 1995; Gunderson 1997). The ratio of reproductive biomass to the mass of the parent definitely does not represent the proportion of energy flowing through the organism that is allocated to reproduction (Stearns 1992). Although this problem has been recognized (Havenhand \& Todd 1989; Grant 1990) and in exceptional cases the cost of producing extraembryonic material (Hughes \& Roberts 1980; Perron \& Corpuz 1982; Lee \& Strathmann 1998) has been quantified, our results suggest that the current approach for estimating parental investment among marine invertebrates urgently needs revision.

Finally, we suggest that different solutions for facilitating oxygen diffusion in egg masses, or actively providing oxygen to embryos, may be a necessary investment among brooding species. This implies an additional cost of reproduction for marine invertebrates. The relationship between oxygen provision to embryos and the cost of oxygen provision may affect the trade-offs between brooding or broadcasting and may have far reaching consequences, since the potential for dispersal of brooding and broadcasting species during early stages differs, affecting population dynamics, ranges of distribution of species, and extinction rates of marine invertebrates (Jablonski \& Lutz 1983). All these factors are of major importance in adopting management and conservation strategies (Allison et al. 1998).

\section{ACKNOWLEDGEMENTS}

We thank many colleagues from the Ecophysiology laboratory (AWI). Antonio Baeza, Francisco Bozinovich,
Juan Carlos Castilla, Paula Neill, Karina Nielsen, Rubén Sotu, Richard Strathmann, and two anonymous reviewers made helpful comments on the manuscript. We thank the Humboldt Foundation and the Alfred-Wegener-Institut (AWI) for supporting this project. MF acknowledges support from FONDAP O \& BM, Program \# 3 (Chile) during the preparation of the manuscript.

\section{REFERENCES}

Allison, G., Lubchenco, J. \& Carr, M. (1998). Marine reserves are necessary but not sufficient for marine conservation. Ecol. Application, 8, S79-S92.

Brey, T. (1995). Temperature and reproductive metabolism in macrobenthic populations. Mar. Ecol. Prog. Series, 125, 87-93.

Brown, J.L. (1987). Helping and Communal Breeding in Birds. Princeton University Press, Princeton.

Browne, R.A. \& Russell-Hunter, W.D. (1978). Reproductive effort in mollusks. Oecologia, 37, 23-27.

Chaffee, C. \& Strathmann, R.R. (1984). Constraints on egg masses. I. Retarded development within thick egg masses. J. Exp. Mar. Biol. Ecol., 84, 73-83.

Clutton-Brock, T.H., Albon, S.D. \& Guinness, F.E. (1981). Parental investment in male and female offspring in polygynous mammals. Nature, 289, 487-489.

Cohen, C.S. \& Strathmann, R.R. (1996). Embryos at the edge of tolerance: effects of environment and structure of egg masses on supply of oxygen to embryos. Biol. Bull., 190, 8-15.

Crisp, D.J. (1959). The rate of development of Balanus balanoides embryos in vitro. J. Anim. Ecol., 28, 119-132.

Edwards, E. (1979). The Edible Crab and its Fisheries in British Waters. Fishing News Books Ltd, Farnham, Surrey.

Grant, A. (1990). Mode of development and reproductive effort in marine invertebrates: should there be any relationship? Func. Ecol., 4, 128-130.

Gunderson, D.R. (1997). Trade-off between reproductive effort and adult survival in oviparous and viviparous fishes. Can. J. Fish Aquat. Sciences, 54, 990-998.

Hartnoll, R.G. \& Paul, K. (1982). The embryonic development of attached and isolated eggs of Carcinus maenas. Int. J. Invertebrate Reprod., 5, 247-252.

Havenhand, J.N. \& Todd, C.D. (1989). Reproductive effort of the nudibranch molluscs Adalaria proxima and Onchidoris muricata: an evaluation of techniques. Func. Ecol., 3, 153-163.

Howard, A.E. (1982). The distribution and behavior of ovigerous edible crabs (Cancer pagurus) and consequent sampling bias. J. Du Conseil, 40, 259-261.

Hughes, R.N. \& Roberts, D.J. (1980). Reproductive effort of winkles (Littorina spp.) with contrasted methods of reproduction. Oecologia, 47, 130-136.

Jablonski, D. \& Lutz, R. (1983). Larval ecology of marine benthic invertebrates: paleobiological implications. Biol. Rev., $58,21-89$.

Krebs, J.R. \& Clutton-Brock, T.H. (1991). The Evolution of Parental Care. Princeton University Press, Princeton.

Kuris, A.M. (1991). A review of patterns and causes of crustacean brood mortality. In: Crustacean Issues 7: Crustacean Egg Production (eds Wenner, A. \& Kuris, A.). A.A. Balkema, Rotterdam, The Netherlands, pp. 117-141. 
Lack, D. (1968). Ecological Adaptations for Breeding in Birds. Methuen, London.

Lee, C.E. \& Strathmann, R.R. (1998). Scaling of gelatinous clutches: effects of sibling competition for oxygen on clutch size and parental investment per offspring. Am. Naturalist, 151, 293-300.

Naylor, J.K. \& Taylor, E.W. (1999). Heart rate and gill ventilation in ovigerous and non-ovigerous edible crabs, Cancer pagurus: the effect of disturbance, substrate and starvation. Mar. Freshwater Behav. Physiol., 32, 129-145.

Naylor, J.K., Taylor, E.W. \& Bennet, D.B. (1997). The oxygen uptake of ovigerous edible crabs (Cancer pagurus) and their eggs. Mar. Freshwater Behav. Physiol., 30, 29-44.

Naylor, J.K., Taylor, E.W. \& Bennett, D.B. (1999). Oxygen uptake of developing eggs of Cancer pagurus (Crustacea: Decapoda: Cancridae) and consequent behaviour of the ovigerous females. J. Mar. Biol. Assoc U.K., 79, 305-315.

Pechenik, J.A. (1986). The encapsulation of eggs and embryos by molluscs: an overview. Am. Malacol. Bulletin, 4, 165-172.

Perron, F.E. (1981). Egg size distribution among closely related marine invertebrate species: are they bimodal or unimodal? Am. Naturalist, 118, 749-755.

Perron, F.E. \& Corpuz, G.C. (1982). Costs of parental care in the Gastropod Conus pennaceus: age specific changes and physical constraints. Oecologia, 55, 319-324.

Shine, R. (1988). Parental care in reptiles. In: Biology of the Reptilia (ed. Gans, C.). Alan Liss, New York, pp. 276-329.

Stearns, S.C. (1992). The Evolution of Life Histories. Oxford University Press, Oxford.

Strathmann, R.R. \& Strathmann, M.F. (1982). The relationship between adult size and brooding in marine invertebrates. Am. Naturalist, 119, 91-101.

Strathmann, R.R. \& Strathmann, M.F. (1995). Oxygen supply and limits on aggregation of embryos. J. Mar. Biol. Assoc. UK, $75,413-428$.
Strathmann, R. \& Chaffee, C. (1984). Constraints on eggs masses. II. Effects of spacing size and number of eggs on ventilation of masses of embryos in jelly, adherent group, or thin-walled capsules. J. Exp. Mar. Biol. Ecol., 84, 85-93.

Vance, R.R. (1973). On reproductive strategies in marine benthic invertebrates. Am. Naturalist, 107, 339-352.

Wheatly, M.G. (1981). The provision of oxygen to developing eggs by female shore crabs (Carcinus maenas). J. Mar. Biol. Assoc. U.K., 61, 117-128.

Williamson, H. (1904). Contributions to the life-histories of the edible crab (Cancer pagurus) and of other decapod Crustacea. Report Fish Board Scotland, 22, 100-140.

Wilson, E.O. (1971). Insect Societies. Harvard University Press, Cambridge.

Zeh, D.W. \& Smith, R.L. (1985). Paternal investment by terrestrial arthropods. Am. Zool., 25, 785-805.

\section{BIOSKETCH}

Miriam Fernandez currently studies oxygen limitation in embryo masses of marine invertebrates, especially the role of female behaviour in providing oxygen to the embryos and the cost of brooding.

Editor, F. Boero

Manuscript received 12 May 2000

First decision made 19 June 2000

Manuscript accepted 21 July 2000 